\title{
Co-limitation of Soil Iron in Root Nodulation and Chlorophyll-Bean Formation of Yardlong Bean Plants in Tropical Humid Environment
}

\author{
Hong $\mathrm{Li}^{*}$ \\ Chinese Academy of Tropical Agricultural Science, Environment and Plant Protection Institute, Haikou, \\ Hainan, 571101 China. \\ * Corresponding author. Tel.: 86-898-66969229; email: hongliss@hotmail.ca \\ Manuscript submitted March 15, 2015; accepted May 15, 2015. \\ doi: 10.17706/ijbbb.2015.5.4.232-240
}

\begin{abstract}
Soil iron (Fe) and antagonistic effects of rhizobial inoculants and organic C involved in legume root nodulation, leaf chlorophyll formation and crop yield performance are not well understood. Soil Fe, a critical micronutrient for plant growth, is highly variable in the humid, acidic environments. The objectives of the study were to assess the co-limitation of soil Fe concentrations on whole plant development, root nodulation, chlorophyll formation and marketable yield of yardlong beans (Vigna unguiculata subsp. sesquipedalis) in the humid, acidic environment. The field study was conducted in a rice-vigna rotation field in tropical Hainan Island during 2012-2013. The experimental treatments consisted of two levels of chicken compost ( 0 and $1.8 \mathrm{Mg} \mathrm{ha}^{-1}$ ) and vigna rhizobial inoculants at the rates of $0,8,16$ and $24 \mathrm{~g}$ per kg of seeds, arranged in a split-plot design. The results showed that soil Fe concentrations were spatially variable across the field. In spite of soil Fe variability, yardlong-bean plants (cv. 'Youfeng-3') responded strongly to the compost and inoculant treatments. Root nodulation, whole plant biomass and marketable fresh beans yields were significantly higher in the compost and inoculant plots compared to the control $(P<0.05)$. Soil Fe concentrations could explain $23 \%$ of the variations in leaf chlorophyll content. Fresh bean marketable yields in early bearing stage increased strongly with soil Fe concentrations $\left(R^{2}=0.44\right)$, but there was a decline trend for late-season fresh bean yields plotted against soil Fe concentrations. It was concluded that co-limitation of excess soil Fe ( $>400 \mathrm{mg} \mathrm{kg}^{-1}$ ) could prohibit legume plant chlorophyll and yield formation. Rhizobia inoculants and organic $\mathrm{C}$ help reduce soil Fe activity in the humid, acidic environment.
\end{abstract}

Key words: Fabaceous crop root nodulation, leaf chlorophyll, rhizobial inoculation, soil acidity, soil iron, yardlong-beans.

\section{Introduction}

Iron ( $\mathrm{Fe}$ ) ions and active $\mathrm{H}^{+}$are often dominant elements in paddy soils in the humid, acidic environments [1]-[3]. Organic matter and nutrient levels are typically low and variable in such soils due to rapid decomposition from high temperatures and leaching from high rainfall [2]. Iron is a critical micronutrient for plant growth, nutrient transport, nitrogen fixation, chlorophyll biosynthesis and photosynthesis [1]-[3], [4]-[7]. There is an increasing evidence that Fe deficiency can cause declines in plant photosynthesis, nutrient uptake, structural changes in morphology and functionality of leaves [2], [6], [7]. It is reported that iron deficiency enhanced leghaemoglobin production in nodules [6]. However, excess Fe holding within cells can be toxic to plants [2]. High soil Fe concentrations were associated with citrus tree 
decline in Florida humid, acidic orchards [1].

Soil organic C and macronutrients levels are critical to crop performance [4], [5], [8]-[11]. Soil organic compounds that can hold moisture and nutrients are the most susceptible fraction of the soil to change [5], [12]-[14]. Yardlong beans (Vigna unguiculata subsp. sesquipedalis), a popular, important source of fresh vegetables in tropical areas, is a vigorous climbing annual vine and a genus variety of cowpea (Vigna unguiculata) originally in southern Asia [15]. Yardlong bean plants are extensively grown all year round in the warmer parts of Asia tropical areas [16]. Healthy yardlong beans are highly productive with a fresh bean yield in the range of 28-35 Mg per ha [15], [16] and the crop requires sufficient organic amendments and a large amount of nutrients to keep up the production [15].

Nitrogen requirements by fabaceous crops are derived from soil $\mathrm{N}$ and symbiotically fixed atmospheric $\mathrm{N}$ [8], [9], [17], [18]. If fabaceous seeds are not inoculated with a rhizobial inoculant, high amounts of $\mathrm{N}$ fertilizers have to be required to meet their nutritional needs during the period of bean formation [8], [17]. Yet, relationships between soil Fe, rhizobial inoculants and organic amendments in the humid, acidic soil environments were not well understood.

It was hypothesized that variability in soil Fe concentrations could limit the responses of yardlong-bean plants to organic amendments and rhizobial inoculant input treatments in the humid, acidic soil environments. The objectives of the current study were to (i) investigate the influence of native soil $\mathrm{Fe}$ concentrations on antagonistic effects of chicken compost inputs and rhizobial inoculants on yardlong-bean plant development, root nodulation, chlorophyll and bean formation and (ii) examine the correlation and limitation of native soil Fe concentrations on chlorophyll and bean formation of yardlong-bean plants in the humid, acidic environments.

\section{Materials and Methods}

\subsection{Field Experiment Description}

The yardlong bean experiment was conducted during 2012 and 2013 on Wudongwen Farms, a multi-crop commercial farm registered in the tropical winter vegetable programs of Hainan Province, situated in Dingan County in the northern Hainan Island, China (19037'34.4"N, 11020'48.6"E, elevation 58 m above the Southern China Sea). In the areas, the climate is a humid, tropical climate monsoon with hot summers and warm winters. The annual temperature averages $23.8^{\circ} \mathrm{C}$ and annual rainfall totals $2430 \mathrm{~mm}$. The growing degree-days for plants are up to $6200^{\circ} \mathrm{C}$ (base temperature of $5^{\circ} \mathrm{C}$ ). The winter temperatures in this tropical island are warm $\left(18 \pm 6^{\circ} \mathrm{C}\right.$ daily) and the monthly rainfall is less $(102 \pm 23 \mathrm{~mm})$, suitable for vegetable production. Because of the suitability of winter temperatures for general growth of vegetables, Hainan has been one of the biggest winter vegetable production bases in China. Yardlong beans are among the top favorable fresh vegetables grown in the winter in Hainan.

The soil in the experimental field was a paddy soil derived from granites, classified as an Udic Ferralosol in Chinese Soil Taxonomy [18], known as an Ultisol in the American Soil Classification System. To insure healthy crop production, the farm has practiced an annual crop rotation with three crops (bean-fruit-rice) in farming management. The previous crop was banana prior to conducting the yardlong bean study, which followed by a short-season small fruit crop, Japanese melon (Cucumis melo L.).

The experimental treatments consisted of chicken compost inputs at the rates of 0 and $1.8 \mathrm{Mg} \mathrm{ha}^{-1}$ on a dry weight basis and vigna rhizobial inoculant applications at the rates of $0,8,16$ and $24 \mathrm{~g} \cdot$ per $\mathrm{kg}$ of seeds. The chicken-compost was sampled for determi-nation of microbial properties, organic $\mathrm{C}$, mineral N, P, K, Ca, $\mathrm{Mg}, \mathrm{B}, \mathrm{Fe}, \mathrm{Mn}, \mathrm{Cu}$ and $\mathrm{Zn}$ concentrations. The inoculants named Jiangduo were obtained from Lingxian Shengwu Inc., Qinhuangdao, Hebei. The commercial inoculants were cultured for examination of active bacteria, actinomycetes and fungi analyses. 
The yardlong bean cultivar was 'Youfeng-3', a popular cultivar for production of high quality fresh beans for exportation. The compost and inoculant treatments were applied using a split-plot design with chicken compost in the main plots in five blocks in the field. Row beds for planting were raised for $0.35 \mathrm{~m}$ to facilitate drainage. The row beds were $0.9 \mathrm{~m}$ in width. The spacing between two rows was $0.5 \mathrm{~m}$. Soil samples were taking at 0-0.25 $\mathrm{m}$ at GPS-points in each plot using a soil auger.

After the soil sampling, the chicken compost treatments were then applied onto the raised beds. The requirements of NPK macronutrients for yardlong bean plants were respective the uniform rate of $25 \mathrm{~kg}$ ha- ${ }^{-1}$ on a basis of $\mathrm{N}_{2} \mathrm{P}_{2} \mathrm{O}_{5}$ and $\mathrm{K}_{2} \mathrm{O}$ nutrients based on the soil testing and regional recommendations. The NPK rates were respectively supplied using gradual calcium ammonium nitrate $\mathrm{NH}_{4} \mathrm{NO}_{3}$-Ca (27-0-0), monocalcium phosphate $\mathrm{Ca}\left(\mathrm{H}_{2} \mathrm{PO}_{4}\right)_{2}$ (0-46-0) and muriate of potash $\mathrm{K}_{2} \mathrm{O}(0-0-60)$. The chemical fertilizers were mixed and applied by hand spreading to the raised seed beds. Then the beds were immediately mulched using a black plastic mulch.

The inoculant treatments were mixed with seeds an hour prior to the seeding and the inoculanted seeds were sowed directly in a double-drill in the raised beds. The spacing between the double-drill was $0.4 \mathrm{~m}$ and the seeds were spaced $0.30 \mathrm{~m}$ in the row. There were a total of 40 plots $(2 \times 4 \times 5)$ and each plot sized $0.9 \mathrm{~m} \times 7 \mathrm{~m}$.

Yardlong bean seed emergence occurred 4 days after seeding in the field. Tri-foliar leaves appeared within a week after seeding. Scaffolding was provided for vigna vine climbing in the second week after seeding. Plants started to flower within 8 weeks (about 50 days) after sowing and the green pods were quickly grown within 10 days after flowering. Irrigation (usually drip irrigation) did not take place because of sufficient and regular seasonal rainfall patterns. Disease and insect controls and other crop cares including fungicide applications were done based on the field survey and regional recommendation from the local agricultural services.

\subsection{Plant and Soil Measurements}

In each experimental plot, three Global Positioning System (GPS) measurement points were set up for site-specific plant and soil measurements. First harvest of fresh beans was done by hand on 6 March, i.e. 76 days after seeding. The plants continued to bloom and bear and fresh beans were continuously harvested on a basis of daily picking for 29 days until 16 April. The production season lasted a total of 116 days.

Five whole plants of yardlong beans were randomly taken in each plot for assessing root nodulation, root lengths, leaf numbers and fresh biomass and dry matter of leaves, stems and roots at full blooming and final harvest. Plant samples were dried at $70^{\circ} \mathrm{C}$ in the oven for 72 hours then plant dry matter was measured. Stem allantoin, amino acids and nitrate were determined to estimate plant ureide concentrations and plant $\mathrm{N}$ derived from $\mathrm{N}$ fixation. These results were not reported in the current paper.

Soil macro- and micro-nutrient components $\left(\mathrm{NO}_{3}, \mathrm{NH}_{4}\right.$ and extractable $\mathrm{P}, \mathrm{K}, \mathrm{Fe}$ and $\left.\mathrm{Zn}\right)$ were quantified for each plot. Air-dried soil samples were analyzed for $\mathrm{pH}$ (soil/water 1:1) using a Leici pH/ions meter. Soil gravimetric water content was determined by oven-drying for estimating water holding and soil organic $\mathrm{C}$ content (OC) was determined using the Walkley-Black procedure [5].

The Mehlich-3-extracted soil $\mathrm{Fe}, \mathrm{Zn}, \mathrm{Cu}, \mathrm{Mn}, \mathrm{K}, \mathrm{Ca}$ and $\mathrm{Mg}$ concentrations were determined using atomic absorption methods. The Mehlich-3 extracted soil $\mathrm{P}$ concentrations were determined by ascorbic-acid colorimetrical analysis using a SSI UV/Visible-spectrophotometer (Shimadzu, Tokyo, Japan). The $2 \mathrm{~N}-\mathrm{KCl}$-extracted soil $\mathrm{NH}_{4}$ and $\mathrm{NO}_{3}$ concentrations were measured using the Kjeldahl procedure [9] using a VELP automatic rapid distillation \& titration system (VELP Scientifica, Usmate, Italy).

\subsection{Calculations and Data Statistics}

Total marketable fresh bean yields were estimated as the sum of daily marketable bean yields. Short $(<$ 
$0.3 \mathrm{~m}$ ) size fresh beans were not counted as marketable yields. Analysis of variance, descriptive statistics, correlation and regression analysis of all measured data were done using PROC GLM, PROC UNIVARIATE and PROC CORR [19]. Homogeneity of datasets was verified using the Bartlett Test, normality and residual distribution of data sets were confirmed using PROC UNIVARIATE. Means of treatments were compared using the Least Significant Difference (LSD) test [19].

\section{Results}

\subsection{Soil Characteristics and Plant Vigor}

The soil in the rooting depth $(0.20 \mathrm{~cm})$ was acidic $(\mathrm{pH} \mathrm{5.3 \pm 0.4)}$ and poor in organic matter (10.4-11.4 g $\mathrm{kg}^{-1}$ ). Soil Fe ions were the dominant element (267-483 $\mathrm{mg} \mathrm{kg}^{-1}$, Table 1). The KCl-extracted $\mathrm{NO}_{3}-\mathrm{N}^{-}$and $\mathrm{NH}_{4}-\mathrm{N}$ and other Mehlich-III-extracted cation concentrations ( $\mathrm{Mn}, \mathrm{Cu}$ and $\mathrm{Zn}$ ) were low. Soil Fe, P, K, Ca, Mg and $\mathrm{Zn}$ concentrations were significantly different within the divided zones across the field (Table 1).

Table 1. Comparisons of Means of Soil Nutrient Concentrations

\begin{tabular}{llllll}
\hline Zones & OC $\dagger$ & Fe $\dagger$ & Mn $\dagger$ & $\mathrm{Zn} \dagger$ & $\mathrm{Cu} \dagger$ \\
\hline South & $11.4 \mathrm{a}$ & $491.6 \mathrm{a}$ & $8.80 \mathrm{c}$ & $1.67 \mathrm{~b}$ & $0.68 \mathrm{ab}$ \\
Center & $11.1 \mathrm{a}$ & $448.2 \mathrm{~b}$ & $18.2 \mathrm{a}$ & $2.02 \mathrm{a}$ & $0.77 \mathrm{a}$ \\
& & & & 1.90 & \\
North & $10.4 \mathrm{ab}$ & $426.3 \mathrm{bc}$ & $12.9 \mathrm{~b}$ & $\mathrm{ab}$ & $0.72 \mathrm{a}$ \\
\hline
\end{tabular}

† OC (organic C) in $\mathrm{g} \mathrm{kg}^{-1}$, and Fe, $\mathrm{Mn}, \mathrm{Zn}$ and $\mathrm{Cu}$ in $\mathrm{mg} \mathrm{kg}^{-1}$. Least Significant Difference (LSD) test. The means with the same letters are not significantly different at $\alpha<0.05$.

The applied chicken-compost treatments contained $92 \%$ of organic C, $1.7 \% \mathrm{~N}, 2.1 \% \mathrm{P}, 2.3 \% \mathrm{~K}, 11.6 \% \mathrm{Ca}$, $0.6 \% \mathrm{Mg}, 0.03 \% \mathrm{~B}, 0.5 \% \mathrm{Cu}$ and $0.1 \% \mathrm{Zn}$ on a dry weight basis. Per gram of applied inoculants contained an active bacterial density of $(1.14 \pm 0.28) \times 10^{11}$ and the actinomycete numbers were up to $(1.5 \pm 0.11) \times 10^{7}$. No fungi were found in the inoculants.

The flowers and green pods of yardlong bean plants formed in pair-groups. There were on average 19.7 \pm 3.6 tri-leaves (mean \pm standard deviation) in each plant ( $n=120$ plants, Table 2 ). Three whole plants were sampled in each plot at the first blooming stage. The biomass and dry matter of different plant parts were in the order of stems $>$ leaves $>$ roots (Table 2). The data were normally distributed among the treatments except the total nodules (kurtosis $>3$, Table 2).

Table 2. Descriptive Statistics of Total Nodule Numbers, Total Nodule Weights, Tri-foliar Leaf Numbers, Biomass and Dry Matter per Plant

\begin{tabular}{llllll}
\hline \multirow{2}{*}{ Variables $\dagger$} & \multirow{2}{*}{ Total nodules } & \multirow{2}{*}{ Tri-leaves } & \multicolumn{3}{c}{ Biomass per plant $(\mathrm{g})$} \\
\cline { 4 - 6 } & & & Leaves & Stems & Roots \\
\cline { 4 - 6 } Mean & 22.4 & 19.7 & 58.4 & 78 & 6 \\
Stand. dev. & 17 & 3.9 & 11.8 & 19.3 & 1.7 \\
Variance & 289 & 15.6 & 138.4 & 371.6 & 2.8 \\
Kurtosis & 5.3 & -0.6 & 0.4 & 1 & 1.9 \\
Skewness & 2.1 & 0.1 & 0.4 & 0.8 & -0.6 \\
Range & 84.7 & 15.7 & 56.2 & 95.5 & 9.4 \\
Min & 4.3 & 12.7 & 29.1 & 35 & 0.4 \\
Max & 89 & 28.3 & 85.3 & 130.5 & 9.8 \\
\hline \multicolumn{2}{c}{$\dagger n=15$ for each mean and standard deviation. }
\end{tabular}

There were significant differences in whole plant biomass among the compost and inoculant treatments. Plants in the compost plots had a stronger growth-vigor with higher whole- plant biomass $(156 \pm 39 \mathrm{~g}$ plant $\left.^{-1}\right)$ than in the control $\left(104 \pm 27\right.$ g plant $\left.^{-1}\right)$. Plants in the inoculanted plots also grew significantly more vigorously than these in the control plots (Fig. 1). The means with the same letters are not significantly 
different at $\alpha<0.05$.

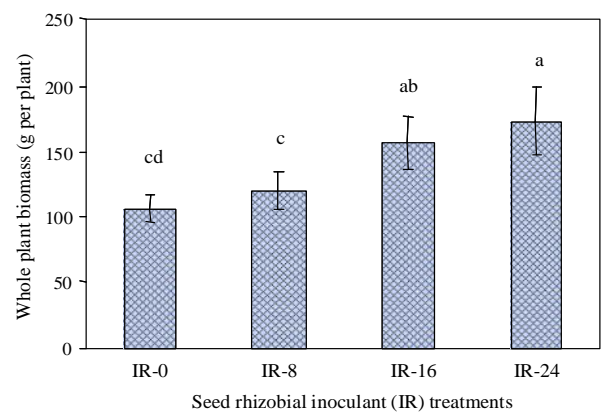

Fig. 1. Comparison of means of yardlong beans whole plant biomass between the seed rhizobial inoculant treatments (IR) using least significant difference (LSD) test. Each bar represents the mean and standard deviation values $(n=15)$.

\subsection{Effects of Rhizobial Inoculants and Compost Inputs on Root Nodulation and Bean Yields}

Yardlong bean root nodulation occurred from vegetative stage through the long period of bean setting stage. The root nodules formed in fluorescence on roots. The nodule numbers varied between $22.4 \pm 17.3$ nodules per plant and nodule weights ranged between $0.12-4.00$ g per plant (Table 2). The root nodulation was significantly stronger at the higher IR treatments $\left(29.5\right.$ and 30.7 nodules per plant for the $I_{16}$ and IR 24 levels) compared to the control (17.8 nodules per plant), with a determined value LSD $=5.7$ nodules per plant.

The yardlong bean plant development was marked by the continuously blooming and bean setting throughout the growing season. The highest dairy marketable yield of fresh beans was $1.63 \pm 0.57 \mathrm{~kg}$ per plot $(n=40)$, harvested in early bean bearing stage on March $8^{\text {th }}$, i.e. 2 days after the start of bean picking. Most of the daily marketable yields of fresh beans varied between $0.82-1.53 \mathrm{~kg} / \mathrm{plot}(n=40)$ and the lower daily marketable yield averaged $0.3-0.7 \mathrm{~kg} / \mathrm{plot}(n=40)$ measured in 4 weeks after the start of the bean harvesting.

The fresh bean marketable yields were significantly higher in the composted plots (37.8 $\left.\mathrm{Mg} \mathrm{ha}^{-1}, n=36\right)$ than in the control plots (32.3 $\mathrm{Mg} \mathrm{ha}^{-1}, n=4$ ) (graph not shown). Depending on the rhizobial inoculant inputs, total marketable yields of fresh beans were also significantly higher (mean $37.6 \mathrm{Mg} \mathrm{ha}^{-1}$ ) for the inoculant treatments than the control (32.3 $\left.\mathrm{Mg} \mathrm{ha}^{-1}\right)$, with a comparison value $\mathrm{LSD}=4.1 \mathrm{Mg} \mathrm{ha}^{-1}$.

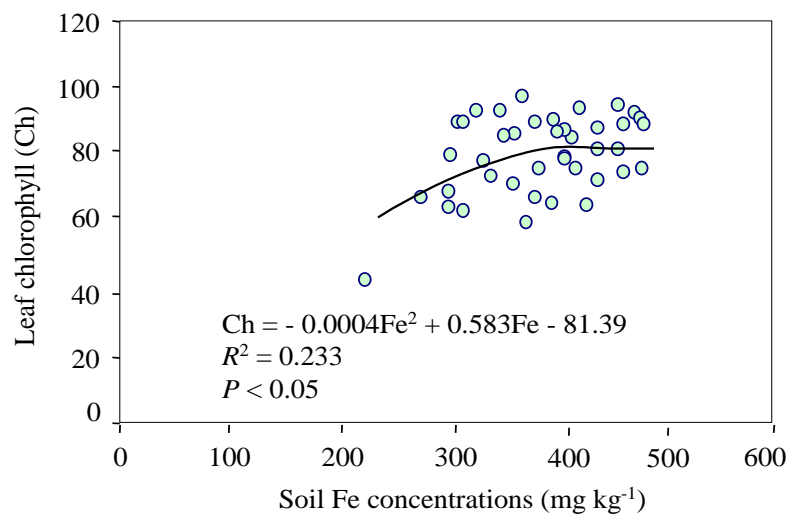

Fig. 2. Regression patterns between yardlong bean leaf chlorophyll content and soil Fe concentrations. 


\subsection{Co-limitation of Soil Fe in Chlorophyll Formation and Fresh Bean Yields}

As the dominant ion in the soil, Fe ion concentrations had an impact on leaf chlorophyll formation, as shown plant leaf chlorophyll content (SPAD value) of increased with increasing soil Fe concentrations (Fig. 2). $92 \%$ of the leaf chlorophyll content ranged between 60 and $95 \%$. Soil Fe ions alone could explain $23 \%$ of the variation in leaf chlorophyll formation.

Fresh bean marketable yields increased strongly with soil Fe concentrations in early bearing stage $\left(R^{2}=\right.$ 0.44, Fig. 3(A)). The fresh bean yields determined on March 8 (i.e. just two days into harvesting) varied between 2.86-5.14 $\mathrm{Mg} \mathrm{ha}^{-1}$, the increase trend in fresh bean yields was nearly linear (Fig. 3(A)). However, the fresh bean yields determined on April 8 (i.e. 4 weeks after the initial harvesting) varying 0.79-1.04 Mg ha $^{-1}$, representing only $13-36 \%$ of the yields measured in early bean setting stage. The plotted curves of fresh bean yields against soil Fe ions was showed a decline trend at the late bearing stage, which explained $21.8 \%$ of the variation in fresh bean yields (Fig. 3(B)). Bean marketable yields declined when soil Fe concentrations became too high (> $400 \mathrm{mg} \mathrm{kg}^{-1}$, Fig. 3(A)).

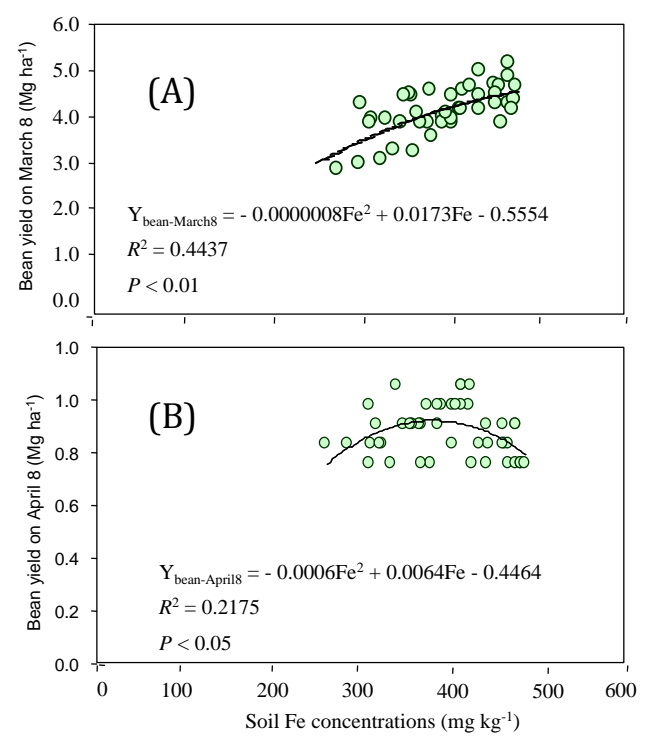

Fig. 3. Influencing patterns of soil Fe ions on fresh bean yields of yardlong bean plants on early baring stage measured on March 8 (A) and on late baring stage measured on April 8 (B). $n=40$ each variable.

\section{Discussion}

Favorable conditions of soil rhizobial bacteria and organic materials are critical to crop productivity [4], [12]. A low and limiting rhizobia environment (control plot IR-0) could reduce yardlong bean plant growth (Fig. 1). The increase patterns in dependence on rhizobial nioculant treatments for whole plant biomass showed the positive effects of rhizobial nioculants in plant development and bean setting, although the soil nutrient concentrations were variable across the field (Table 1). Yardlong bean plant growth improvement might be beneficial from seed inoculation of rhizobial bacteria [15]. Strategies that increased the numbers of effective rhizobia present by adding rhizobia inoculants in soil were beneficial to root nodulation, and therefore plant growth vigor.

Yardlong bean plant is a true legume. The main growth stages of yardlong bean plants are vegetative stage and the reproductive stage [14], [15]. The significant correlation between leaf chlorophyll content and soil Fe concentrations $(P<0.05$, Fig. 2$)$ showed the positive impact of soil Fe in support of leaf chlorophyll formation. Iron is a required, essential plant nutrient for plant growth and reproduction. Although Fe is a 
micronutrient for plant growth, Fe ions are involved in many important compounds and physiological processes in plants such as chlorophyll synthesis [2]. It should be in this reason that the relations between yardlong bean leaf chlorophyll content and soil Fe concentrations were significantly correlated.

The stronger coefficient of determination between soil Fe concentrations and fresh bean marketable yields measured in early stage than in late stage (Fig. 3) suggested that soil Fe could affect more strongly bean formation in early bean setting stage. This might be because of the promoting leaf chlorophyll formation by soil Fe ions to enhance plant photosynthesis for stronger bean formation in the early bean setting stage. When yardlong bean leaves became decrepit, the effects of soil Fe ions were also reduced on bean formation (Fig. 3).

Co-limitation of soil Fe ions in yardlong bean productivity was shown by the plateau appeared in the polynomial regressions curves for leaf chlorophyll (Fig. 2) and bean yield (Fig. 3). Too much Fe ions in the soils ( $>400 \mathrm{mg} \mathrm{kg}^{-1}$ ) could prohibit leaf chlorophyll and bean formation. Fruit tree decline was found to be associated with too much $\mathrm{Fe}$ in the soils in the humid, acidic environment [1]. Small amounts of iron are necessary for chlorophyll production, but too much iron can affect the chlorophyll fluorescence itself, causing it to change and inhibiting plant ability to properly absorb energy from sunlight [4]. It would be useful to further quantify plant Fe uptake to assess plant Fe retention level resulting in decline in leaf chlorophyll and bean formation.

\section{Conclusion}

The antagonistic effects of soil iron, rhizobial inoculants and organic $\mathrm{C}$ were significant on yardlong bean root nodulation, leaf chlorophyll formation and bean productivity. Whole plant development and root nodulation of yardlong bean plants could be improved from seed inoculation of rhizobial inoculants and compost amendment inputs. The positive effects of soil Fe were more pronounced on leaf chlorophyll and bean formation in early bearing stage than in late season. Only high Fe concentrations in the soils $>400 \mathrm{mg}$ $\mathrm{kg}^{-1}$ ) could prohibit legume leaf chlorophyll and bean formation in the humid, acidic environment. It was concluded that co-limitation of soil Fe ions was primary on leaf chlorophyll and bean formation under various rhizobial inoculants and compost inputs in the humid, acidic environment.

\section{Acknowledgment}

The author thanks the supports of Chinese Academy of Tropical Agricultural Science (CATAS)-Environment and Plant Protection (EPPI) Institute Fundamental Scientific Research Funds (project \#hzs1202, \#2013hzs1J006, \#1630042013023), Hainan Province International Research Collaboration Program (Project \#KJHZ2013-10) and Hainan Soil Improvement Key Techniques Research and Demonstration Program (\#HNGDg12015). The author thanks Ms. Wang Xutong for lab analysis assistance and Mr. Wu Tingziu for conducting the field trials on his commercial farm.

\section{References}

[1] Li, H., Futch, S. H., Stuart, R. J., Syvertsen, J. P., \& McCoy, C. W. (2007). Associations of soil iron with citrus tree decline and variability of sand, soil water, $\mathrm{pH}$, magnesium and Diaprepes abbreviatus root weevil: Two-site study. Environmental and Experimental Botany, 59, 321-333.

[2] Meyers, S. R. (2007). Production and preservation of organic matter: The significance of iron. Paleoceanogra, 22, 1-16.

[3] Li, H., Wang, X. T., Salah, A., \& Yang, W. B. (2014). Iron stress and stem ureide nitrogen fixation of yardlong bean and peanut plants in the acidic, tropical Environments. Proceedings of 4th Annual World Congress of Agriculture, Vol. 56. 
[4] Li, H., Parent, L. E., Karam, A., \& Tremblay, C. (2003). Efficiency of soil and fertilizer nitrogen of a sodpotato system in the humid, acid and cool environment. Plant Soil, 251, 23-36.

[5] Li, H., Parent, L. E., Karam, A., \& Tremblay, C. (2004). Potential of Sphagnum peat for improving soil organic matter pool, water holding capacity, bulk density and potato yield in a sandy soil. Plant Soil, $265,353-363$.

[6] Jin, C. W., Li, G. X., Yu, X. H., \& Zheng, S. J. (2010). Plant Fe status affects the composition of siderophore-secreting microbes in the rhizosphere. Annals Botany, 105, 835-841.

[7] Tang, C. X., Robson, A. D., \& Dilworth, M. J. (1990). The role of iron in nodulation and nitrogen fixation in Lupinus angustifolius L. New Phytologist, 114, 173-182.

[8] Diaz, D., Pedersen, P., \& Sawyer, J. E. (2009). Soybean response to inoculation and nitrogen application following long term grass pasture. Crop Science, 49, 1058-1062.

[9] Li, H., Jiang, H., \& Li, T. X. (2011). Broccoli plant nitrogen, phosphorus and water relations at field scale and in various growth media. International Journal of Vegetable Science, 17, 1-21.

[10] Li, H., \& Lascano, R. J. (2011). Deficit irrigation for sustainable water use: Comparison of cotton nitrogen uptake and prediction of lint yield in a multivariate autoregressive state-space model. Environmental and Experimental Botany, 71, 224-231.

[11] Li, H., Li, T., Fu, G., \& Katulanda, P. (2013). Induced leaf intercellular $\mathrm{CO}_{2}$, photosynthesis, potassium and nitrate retention and strawberry early fruit formation under macronutrient limitation. Photosynthesis Research, 115, 101-114.

[12] Li, H., Li, T., Fu, G., \& Hu, K. L. (2014). How strawberry plants cope with limited phosphorus supply: Nursery-crop formation and phosphorus and nitrogen uptake dynamics. Journal of Plant Nutrition and Soil Science, 177, 260-270.

[13] Kanazawa, S., Asakawa, S., \& Takai, Y. (1998). Effect of fertilizer and manure application on microbial numbers, biomass, and enzyme activities in volcanic ash soils. Soil Science and Plant Nutrition, 34, 429-439.

[14] Li, H., Li, T., Gordon, R. J., Asiedu, S., \& Hu, K. (2010). Strawberry plant fruiting efficiency and its correlation with solar irradiance, temperature and reflectance water index variation. Environmental and Experimental Botany, 68, 165-174.

[15] Marutani, M. (2009). Field performance and nodulation of yardlong bean in the humid tropics. International Journal of Vegetable Science, 5, 133-141.

[16] You, Z., Marutani, M., \& Borthakur, D. (2002). Diversity among Bradyrhizobium isolates nodulating yardlong bean and sunnhemp in Guam. Journal of Applied Microbiology, 93, 577-584.

[17] Kawaguchi, M., Kouchi, H., \& Suganuma, N. (2009). Host plant genome overcomes the lack of a bacterial gene for symbiotic nitrogen fixation. Nature, 462, 514-517.

[18] Lin, Q. H., Li, H., Luo, W., Lin, Z. B., \& Li, B. G. (2013). Optimal soil-sampling design in a rubber tree plantation based on fuzzy clustering. Forest Ecology and Management, 308, 214-222.

[19] SAS Institute. (1990). SAS/STAT User's Guide (4th ed.). GLM-VARCOMP. Vers. 6, NC, USA, Cary: SAS Institute.

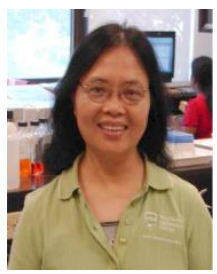

Hong $\mathbf{L i}$ is a nationalized Canadian citizen (1993), and a Canadian professional agrologist (P. Ag.) registered in Nova Scotia. She received her B.Sc. degree in environmental science at Zhongshan University in China (1982), her M.Sc. degree in land management at University of Montpellier III in France (1987), and her Ph.D. degree in crop nutrition/soil environment at Laval University in Canada (1997). 
She did a 5 year postdoctoral research on nutrient management in precision agriculture at Texas A\&M University-North Carolina State University. She also did another 3 year postdoctoral research on plant stress physiology of citrus at University of Florida.

In 2005 she became an edible horticulture research chair at Nova Scotia Agricultural College in Canada. In 2012 she joined Chinese Academy of Tropical Agricultural Science as a distinguished professor. In the same year she was also selected as an adjunct professor -Ph.D. study supervisor at Huazhong Agricultural University.

Her research interests include fruit/vegetable crop nutrition, crop physiology, symbiotic $\mathrm{N}$ fixation and plant/soil N-P assimilation mechanism. She teaches university's courses of fruit production and vegetable science. She has contributed to improve nutrient use efficiency of many crops including strawberry, citrus, longan, soybean, broccoli, cauliflower, potato, cotton, etc. And she has published in some high impact-factor international journals including Photosynthesis Research, Soil Biology and Biochemistry, Environmental and Experimental Botany, Applied Soil Biology, etc.

She is now a member of International Society for Horticultural Science, American Society of Agronomy, American Society of Crop Science and Soil Science Society of America. She has received outstanding research certificate from North Carolina State University (2002), leaders opportunity fund award from Canada Foundation for innovation (2007), outstanding research award from Canadian Society of Agronomy (2011) and recognition certificates from Marquis Who's Who in Science and Engineering (2004-2013). 